ZOOLOGIA 32 (2): 145-150, April 2015

http://dx.doi.org/10.1590/S1984-46702015000200005

\title{
Two new species of Emersonella (Hymenoptera: Eulophidae: Entedoninae) from the Brazilian Atlantic Forest
}

\author{
Thiago M. Alvarenga ${ }^{1,4}$, Valmir A. Costa ${ }^{2}$, Christer Hansson ${ }^{3} \&$ César F. Carvalho $^{1}$ \\ 'Departamento de Entomologia, Universidade Federal de Lavras. Caixa Postal 3037, 37200-000 Lavras, MG, Brazil. \\ ${ }^{2}$ Centro Experimental do Instituto Biológico, Instituto Biológico. Caixa Postal 70, 13001-970 Campinas, SP, Brazil. \\ ${ }^{3}$ Entomology Department, The Natural History Museum, London SW7 5BD, United Kingdom. \\ ${ }^{4}$ Corresponding author. E-mail: marinho.bio@gmail.com
}

\begin{abstract}
Emersonella Girault, 1916 is a wasp genus including species that parasitize Chrysomelidae (Coleoptera) eggs, mainly Cassidinae. It occurs only in the Americas, and is primarily distributed in the Neotropical Region. In this paper two new species of Emersonella from the Atlantic Forest of southeastern Brazil are described and compared to similar species. Emersonella appendigaster sp. nov. is characterized by an elongate last gastral tergite in female, thoracic dorsum flat, femora and tibiae yellowish in female, malar sulcus absent, frontal suture slightly down-curved laterally, eyes with scattered hairs, frons and vertex smooth, and propodeum smooth with small anteromedian foveae. Emersonella frieirocostai sp. nov. is characterized by an elongate gaster in the female, at most 1.3 times as long as mesosoma and pointed at apex, propodeum with two large anterolateral foveae, pronotum hardly visible in dorsal view, with posterior part smooth, transverse pronotal carina present and malar sulcus absent. Both species are egg parasitoids of Metriona elatior (Klug, 1820) (Chrysomelidae) which feeds on Solanum viarum Dunal (Solanaceae).
\end{abstract}

KEY WORDS. Cassidinae; eggs; endoparasitoids; host specificity; Solanaceae.

Most species of Eulophidae parasitize phytophagous hosts (LASAlLE 2005). This is also true of Emersonella Girault, 1916, a genus that occurs only in the Americas, and which is primarily distributed in the Neotropical Region (HANSSON 2002). Only two species, E. lemae Girault, 1916 and E. niveipes Girault, 1917 are known from the Nearctic Region.

The Neotropical Emersonella were revised by Hansson (2002) and De Santis (1983). Initially, De Santis (1983) studied the Argentinian, Uruguayan, and Brazilian species, and proposed two generic names as junior synonyms of Emersonella: Pleurotropitiella Blanchard, 1945 and Testudicida De Santis, 1949. Subsequently, Hansson (2002) studied 55 Costa Rican species, of which 47 were described as new, and presented many records from other countries in the Neotropical Region. Later, Hansson $\&$ NisHidA (2004) described another new species from Costa Rica.

Species of Emersonella parasitize Chrysomelidae eggs (Coleoptera), mainly Cassidinae (HANsson 2002, CUIGNET et al. 2007, 2008, Montes \& Costa 2011). However, they can also parasitize Curculionidae eggs (Coleoptera), as is the case with $E$. curculiovora Hansson \& Nishida, 2004 (HANsSON \& NisHIDA 2004).

This paper describes two new Emersonella species. They are egg parasitoids of Metriona elatior (Klug, 1820) (Chrysomelidae), which feeds on Solanum viarum Dunal (Solanaceae).

Solanum viarum is native to South America, occurring in Brazil, Paraguay, and Argentina (MedAL et al. 1996, 1999, RossinI et al. 2002). Introduced and adapted populations have been recorded from India, Nepal, Mexico, Greater and Lesser Antilles, Africa, Burma (Myanmar), Honduras, West Indies, and southeastern United States (USDA 2010). An alien species, S. viarum is considered a noxious plant. It infests pastures, cultivated, and natural areas (MEDAL et al. 1996, USDA 2010). Studies suggest that biological control is the best alternative to suppress this plant (Medal et al. 1996, Rossins et al. 2002). Due to its dietary specialization, the cassidine beetle M. elatior is a putative candidate for the biological control of $S$. viarum in areas where it is not native (Medal et al. 1999, Al Gazi et al. 2008). Natural enemies of $M$. elatior were not known prior to the present work. This information is important to future research on the population regulation of $S$. viarum and M. elatior.

\section{MATERIAL AND METHODS}

Specimens for this study were reared from M. elatior eggs collected from S. viarum growing at the Centro Experimental do Instituto Biológico (CEIB), Campinas, state of São Paulo and Parque Nacional de Passa Quatro, state of Minas Gerais, Brazil. The specimens were killed in ethanol, critical point dried and mounted on cards for further studies. Observations of the specimens were made through a stereomicroscope, Leica M165 C. Digital images were taken with a Leica DFC450 C camera

2015 | Sociedade Brasileira de Zoologia | www.sbzoologia.org.br | www.scielo.br/zool All content of the journal, except where identified, is licensed under a Creative Commons attribution-type BY-NC. 
attached to the stereomicroscope. Light was obtained from a ring with cold light and with a white plastic cup as a filter to disperse the light. Composite images were created using the software Leica Application Suite V 3.8.

Scanning electron microscopy (SEM) images were obtained with a Quanta 250 Scanning Electron Microscope (FEI) at $15.0 \mathrm{kV}$ acceleration voltage, in a low vacuum mode.

Morphological terms follow Hansson (2002), also available as illustrations of the morphological terms at http:// www.neotropicaleulophidae.com.

\section{TAXONOMY}

\section{Emersonella appendigaster sp. nov. Alvarenga, Costa \& Hansson}

Figs. 1-7

Diagnosis. Last gastral tergite in female elongate (more than three times as long as width at base); thoracic dorsum flat; femora and tibiae in female yellowish; malar sulcus absent; frontal suture slightly down-curved laterally (Fig. 1); eyes with scattered hairs; without a small spine above base of forecoxae; frons and vertex smooth (Figs. 1 and 2); propodeum smooth with small (compared to the other species treated here) anteromedian foveae (Fig. 4).

Description. Female. Length of body (excluding 7 th tergite) $1.0-1.3 \mathrm{~mm}$. Scape yellowish-white, remainder of antenna dark. Frons bluish-green and vertex with golden tinges. Mesoscutum and scutellum dark purple. Propodeum metallic blue with golden tinges. Coxae dark and metallic; femora and tibiae yellowish; tarsi yellowish-white with 4th segment brown. Wings hyaline. Petiole dark purple. Female with first gastral tergite golden-green, remaining tergites golden-purple. Antenna as in Fig. 5. Frons and vertex smooth and shiny; frontal suture slightly down-curved laterally. Malar sulcus absent. Occipital margin with a sharp edge (Fig. 2). Eyes with scattered hairs. Ratios of height of head/width of head 1.2, height of eye/malar space/width of mouth opening 2.2/1.0/1.6, distances between posterior ocelli/between posterior ocellus and eye/between posterior ocelli and occipital margin 5.7/3.1/1.0, width of head/ width of thorax across shoulders 1.3. Thoracic dorsum flat. Transverse pronotal carina present. Without a spine above base of forecoxa. With a groove separating mesoscutum from scutellum. Mesoscutum with strong large meshed reticulation; notauli narrow, indicated in anterior one-third. Scutellum with raised reticulation (Fig. 3). Dorsellum flat and smooth. Forewing speculum closed below; with nine admarginal setae. Propodeum with two transverse foveae anterolaterally, with a large anteromedian fovea, propodeal callus with two setae. Petiolar foramen rounded. Ratios: length of forewing/length of marginal vein/ height of forewing 1.6/1.1/1.0; length of postmarginal vein/ length of stigmal vein 0.2. Petiole transverse. Female gaster elongate with last tergite and ovipositor sheaths protruding, last tergite 3.0 times as long as width at base. Ratio of length of mesosoma/length of gaster 0.9 .

Male. Length of body $1.2 \mathrm{~mm}$. Male with scape yellowish-brown, darker along dorsal edge; Femora dark brown; gaster, in dorsal view, with a whitish spot on the first half. Ratio of length of mesosoma/length of gaster 1.0.

Material examined. Holotype female labelled "Brazil, Minas Gerais: Passa Quatro (Parque Nacional de Passa Quatro) 28.xi.2012, Frieiro-Costa, F.A. leg." (MZSP 51832). Paratypes: 12, 7 females and 5 males with same label data as holotype (MZSP 51833-51845). Paratype: 1 female, 02.xi.2002, Gomes, P.A.A. leg. (MZSP 51846).

Remarks. Only three additional species of Emersonella have the last gastral tergite elongated in the female (more than 3.0 times as long as width at base): Emersonella hastata Hansson, 2002, E. metallica Hansson, 2002, and E. terebrata Hansson, 2002. Emersonella appendigaster sp. nov. differs from $E$. hastata and $E$. metallica in having the thoracic dorsum flat, anterolateral foveae on propodeum, malar sulcus absent. Additionally, the female of E. appendigaster has femora and tibiae yellowish. Furthermore, E. appendigaster also differs from E. metallica in having the frontal suture slightly down-curved laterally and eyes with scattered hairs. It differs from E. terebrata in having the frons, vertex, and propodeum smooth, and without a small spine above base of forecoxae.

The female differs from the male mainly by the insertion of the petiole at the top of the gaster (Figs. 6 and 7). Also, the male does not have the last gastral tergite elongated. Male with dark femora and a pale spot on gaster.

Host. Eggs of M. elatior Klug (Coleoptera: Chrysomelidae) on $S$. viarum Dunal (Solanaceae).

Etymology. Name given in reference to the shape and arrangement of the female gaster (Fig. 6).

\section{Emersonella frieirocostai sp. nov. Alvarenga, Costa \& Hansson}

Figs. 8-14

Diagnosis. Female gaster elongate, at most 1.3 times as long as mesosoma and pointed at apex (Fig. 12); propodeum with two large anterolateral foveae (Fig. 9); pronotum hardly visible in dorsal view with posterior part smooth; transverse pronotal carina present; malar sulcus absent.

Description. Female. Length of body $1.2 \mathrm{~mm}$. Scape yellowish-white, remainder of antenna dark. Frons and vertex metallic golden-green. Mesoscutum, scutellum, and propodeum metallic green. Coxae dark and metallic; femora, tibiae, and tarsi yellowish-white. Wings hyaline. Petiole dark purple. First gastral tergite with golden-green tinges, remaining tergites dark brown. Antenna with scape slender and flagellomeres not pedunculated (Fig. 13). Frons and vertex shiny and smooth (Figs. 8 and 10). Frontal suture down-curved laterally (Fig. 8). Malar sulcus absent. Occipital margin with a sharp edge to rounded. 

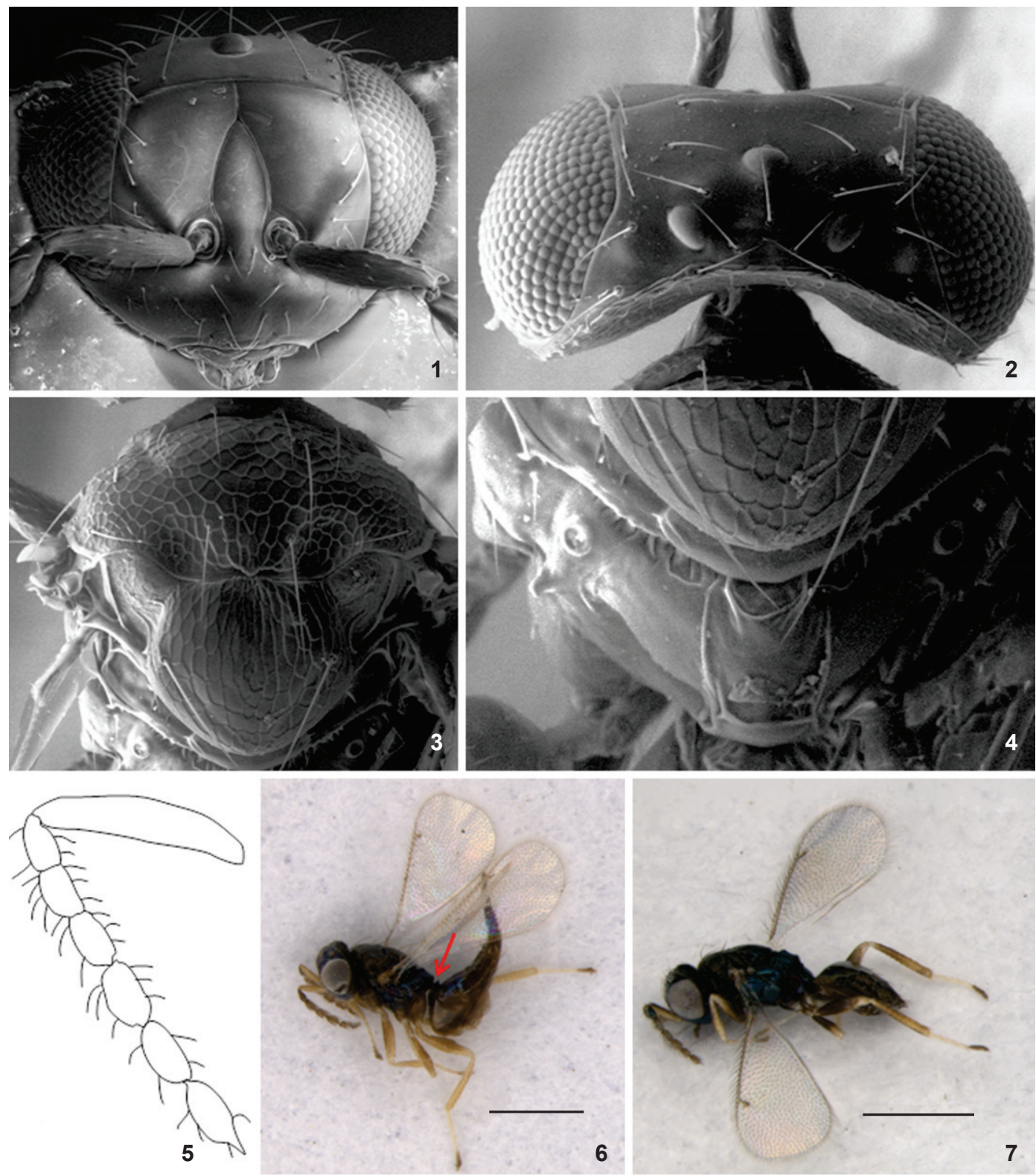

Figs 1-7. Emersonella appendigaster sp. nov., female: (1) frontal view of head; (2) dorsal view of head; (3) dorsal view of mesonotum; (4) dorsal view of scutellum and propodeum; (5) antenna; (6) lateral view of female showing the insertion of petiole at the top of the gaster; (7) lateral view of male. Scale bars: 5-6 $=500 \mu \mathrm{m}$.

Eyes with scattered hairs. Ratios: height of head/width of head 0.7, height of eye/malar space/width of mouth opening 1.6/ 1.0/1.2, distances between posterior ocelli/between posterior ocellus and eye/between posterior ocelli and occipital margin 2.4/2.0/1.0, width of head/width of thorax across shoulders 1.1. Thoracic dorsum convex. Pronotum hardly visible in dorsal view with posterior part smooth; transverse pronotal carina present, although hardly visible. Mesoscutum with raised reticulation; notauli indistinct. Scutellum with raised reticulation. Dorsellum flat and smooth (Fig. 9). Forewing speculum closed posteriorly; with 10 admarginal setae. Propodeum with two rounded foveae anterolaterally, with a short anteromedian fovea, propodeal callus with two setae. Petiolar foramen rounded. Ratios: length of forewing/length of marginal vein/ height of forewing 1.7/1.0/1.0; length of postmarginal vein/ length of stigmal vein 0.8 . Petiole transverse, two times as wide 

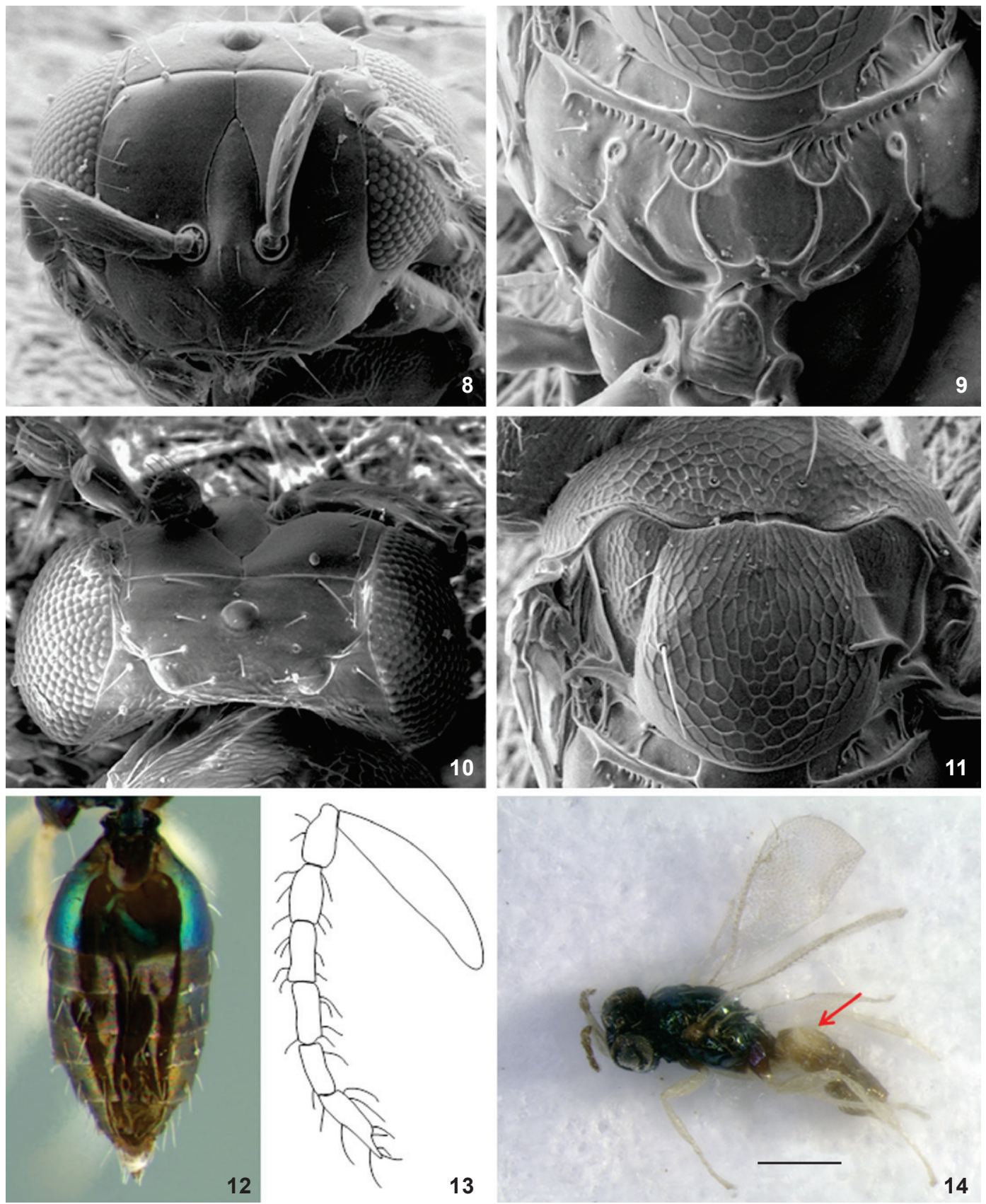

Fig. 8-14. Emersonella frieirocostai sp. nov., female: (8) frontal view of head; (9) dorsal view of propodeum; (10) dorsal view of head; (11) dorsal view of mesonotum; (12) dorsal view of female gaster, showing color of first gastral tergite; (13) lateral view of antenna; (14) lateral view of male showing gaster with a whitish dorsal spot covering the basal half. Scale bar: $14=0.2 \mathrm{~mm}$.

as long. Gaster elongate and acuminate at apex (Fig. 12). Ratio of length of mesosoma/length of gaster: 0.7.

Male. Length of body $1.1 \mathrm{~mm}$. Propodeum golden-green. Femora and tibiae yellowish. Coxae metallic purple. Gaster with a whitish dorsal spot covering the basal half (Fig. 14). Ratio length of mesosoma/length of gaster 0.8 .

Material examined. Holotype female labelled "Brazil, São Paulo: Campinas, 02/III/2012, Alvarenga, T.M. leg. (MZSP 51829). Paratype, 1 female [lacking wings] and 1 male with same label data as holotype (MZSP 51830-51831). 
Remarks. Very close to Emersonella tanigaster Hansson, 2002, but differs from it mainly in having the propodeum with two large anterolateral foveae; also, in E. frieirocostai sp. nov. the transverse pronotal carina is present, although hardly visible, and absent in E. tanigaster. In Hansson's (2002) key, it would run to Emersonella ooecia De Santis, 1983 but E. frieirocostai sp. nov. differs mainly by having the convex thoracic dorsum and other characters indicated in the key.

Host. Eggs of M. elatior (Coleoptera: Chrysomelidae) on S. viarum Dunal (Solanaceae).

Etymology. Name masculine, in genitive singular after Dr. Fernando Antônio Frieiro Costa (Centro Universitário de Lavras, Unilavras), researcher of natural history of Cassidinae and former advisor of the first author.

\section{Proposed modification of the identification key of Hansson (2002) to include the species presently described}

In the key presented by Hansson (2002), E. appendigaster sp. nov. females would run to couplet 3 , change this to $3 \mathrm{a}$ and add:

3a. Malar sulcus absent; scape yellowish-white; femora and tibiae yellowish-white and non-metallic .

E. appendigaster sp. nov.

$3 a^{\prime}$. Malar sulcus present; scape yellowish-brown to dark brown; femora and tibiae dark and metallic 3

To include the male in Hansson's (2002) key to males, the following changes should be included:

20. Scutellum 0.9-1.2 times as long as wide, flat to slightly convex (fig. 471); larger species (1.2-1.4 mm) .. 21

$20^{\prime}$. Scutellum 0.7 times as long as wide, flat (fig. 456); smaller species $(0.7-0.8 \mathrm{~mm})$ ... 22

21(20). Vertex reticulate, hence dull....E. saturata De Santis, 1983

$21^{\prime}$. Vertex smooth and shiny $21 \mathrm{a}$

21a (21'). Scutellum 0.9 times as long as wide; malar sulcus absent E. appendigaster sp. nov.

$21 a^{\prime}$. Scutellum 1.2 times as long as wide; malar sulcus present or only partially absent

E. rubii Hansson, 2002

In Hansson's (2002) key, E. frieirocostai sp. nov. females would run to couplet 24 and the following changes are needed to include this species:

24 (23). Gaster with apex pointed (fig. 95) $24 \mathrm{a}$

$24^{\prime}$. Gaster with apex rounded (as in fig. 141) 25

24a (24). Thoracic dorsum convex; ratio of length of mesosoma gaster 0.7; carina from spiracle reaching the posterior margin of propodeum E. frieirocostai sp. nov.

$24 \mathrm{a}^{\prime}$. Thoracic dorsum flat; ratio of length of mesosoma/length of gaster 0.9 ; carina from spiracle not reaching the posterior margin of propodeum E. ooecia De Santis, 1983

To include the male of $E$. frieirocostai sp. nov. in the key to males of HANsson (2002) the following modifications should be made:

14 (6). With a groove from lateral ocellus toward eye (as in fig. 429 and 11 in this study), groove does not reach eye but continues along and close to eye .............................. 15a

$14^{\prime}$. Without a groove from lateral ocellus toward eye and along eye (as in fig. 457) .... 20

$15 \mathrm{a}$ (14). Scutellum convex, 1.0 times as long as wide; petiole 2.0 times as long as wide; first gastral tergite smooth and shiny E. frieirocostai sp. nov.

$15 \mathrm{a}^{\prime}$. Scutellum variable; petiole at most 1.2 times as long as wide; first gastral tergite smooth or with irregular sculpture ..... 15

\section{DISCUSSION}

Eulophidae is a poorly studied group in tropical America, especially in Brazil. This country, with an area of 8.5 million square kilometers, includes a mosaic of tropical and subtropical ecosystems, and is expected to harbor the greatest diversity of insects on Earth. According to HANSSON (2002), the number of Eulophidae species in tropical America is very large but for the most part the family is very poorly known. CUIGNET et al. (2008) collected several species of undescribed Emersonella from Panama, indicating that a large diversity of these wasps remains to be discovered and documented in tropical America. Thus, given the lack of systematic surveys and more general studies on Brazilian Eulophidae, it is possible that there are more undescribed/ unrecorded species of Emersonella in the country.

\section{ACKNOWLEDGEMENTS}

We authors acknowledge the financial support of $\mathrm{CNPq}$ and CAPES. We also thank Luciana Bueno dos Reis Fernandes and the National Institute of Science and Technology of the Hymenoptera Parasitoids from Brazilian Southeast Region (INCT - Hympar Sudeste) for the SEM photographs of Emersonella.

\section{LITERATURE CITED}

Al Gazi ADF, Gandolfo D, Pitelli RA (2008) Preferência alimentar de adultos de Metriona elatior Klug (Coleoptera: Chrysomelidae, Cassidinae) por diferentes híbridos de Solanun melogena Linnaeus (Solanaceae). Acta Scientiarum, Biological Sciences, 30: 449-454. doi: 10.4025/actascibiolsci.v30i4.5874

Cuignet M, Hance T, Windsor DM (2007) Phylogenetic relationships of egg parasitoids (Hymenoptera: Eulophidae) and correlated life history characteristics of their Neotropical Cassidinae hosts (Coleoptera, Chrysomelidae). Molecular Phylogenetics and Evolution 42: 573-584. doi: 10.1016/ j.ympev.2006.09.005

Cuignet M, Windsor D, Reardon J, Hance T (2008) The diversity and specificity of parasitoids attacking Neotropical Tortoise Beetles (Chrysomelidae, Cassidinae), p. 345-367. In: Jolivet P, 
Santiago-Blay J, Schmitt M (Eds) Research on Chrysomelidae. Leiden, Brill Publishers, 432p.

De SANTIS L (1983) Las especies argentinas, uruguayas y brasileñas del género Emersonella Girault, 1916 (Insecta, Hymenoptera, Eulophidae). Anais da Sociedade Entomológica do Brasil 12(2): 249-259.

Hansson C (2002) Eulophidae of Costa Rica (Hymenoptera: Chalcidoidea) I. Memoirs of the American Entomological Institute 67: 1-290.

Hansson C, K Nishida (2004) A new species of Emersonella (Hymenoptera: Eulophidae), parasitoid on weevil eggs (Coleoptera: Curculionidae), from Costa Rica. Zootaxa 607: 1-6.

LASALLE J (2005) Biology of gall inducers and evolution of gall induction in Chalcidoidea (Hymenoptera: Eulophidae, Eurytomidae, Pteromalidae, Tanaostigmatidae, Torymidae), p. 507-537. In: Raman A, Schaefer CW, Withers TM (Eds). Biology, ecology, and evolution of gall-inducing arthropods. New Hampshire, Science Publishers.

Medal JC, Charudatan R, Mullahey JJ, Pitelli RA (1996) An exploratory insect survey of tropical soda apple in Brazil and Paraguay. Florida Entomologist 79(1): 70-73.

Medal JC, Pitelli RA, Santana A, Gandolfo D, Gravena R, Habeck DH (1999) Host specificity of Metriona elatior, a potential biological control agent of tropical soda apple, Solanum viarum, in the USA. BioControl 44(4): 421-436. doi: 10.1023/A:1009939631229

Montes SMNM, VA Costa (2011) Parasitism in eggs of Paraselenis flava (Coleoptera: Chrysomelidae) in sweet potato (Ipomoea batatas). Revista Colombiana de Entomología 37(2): 249-250.

Rossini A, Gravena RSA, Pitelli RA, Santana AE (2002) Aspectos biológicos de Metriona elatior Klug (Coleoptera, Chrysomelidae, Cassidinae) sobre plantas de Solanum viarum Dunal (Solanaceae). Acta Scientiarum 24: 1433-1438.

USDA (2010) Germplasm Resources Information Network (GRIN). Beltsville, National Germplasm Resources Laboratory, online database, available online at: http:// www.ars-grin.gov/cgi-bin/npgs/html/taxon.pl?317433 [Accessed: August 2014]

Submitted: 3 February 2015

Received in revised form: 17 March 2015

Accepted: 25 March 2015

Editorial responsibility: Gabriel L.F. Mejdalani 